\title{
After the typhoon: how volunteer doctors are bringing medical care to those most in need
}

Doctors of the World was on site to help injured and homeless people in the wake of typhoon Haiyan's devastation of the Philippines, writes Jane Feinmann. The charity is well versed in bringing care to the most vulnerable people all over the world, which is why the BMJ has chosen it for this year's Christmas appeal. Please give generously

\section{Jane Feinmann freelance journalist}

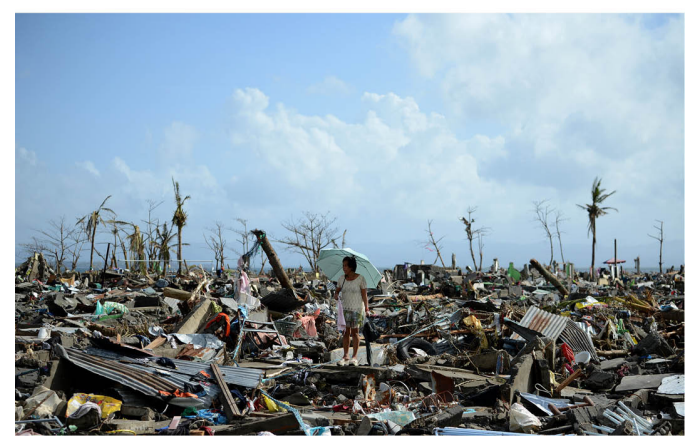

[IImage: NOEL CELLS/AFP/ GETTY IMAGES,

"We are paralysed, full of sorrow, and without hope," says Dr Letlet, the full time doctor at the roofless and ruined San Pablo health centre in a remote village community of 6000 people on the island of Leyte in the Philippines.

In early November typhoon Haiyan destroyed scores of hospitals and health clinics in cities, towns, and villages in the Philippines, just when they were needed most. Millions of survivors, many with severe fractures and experiencing the health consequences of suddenly becoming homeless, are largely managing without everyday medical support.

"People with injuries from the storm have not been treated, and many others who have been made homeless are starting to suffer from fever, flu, and coughs," Letlet explains. Along with the threat of cholera, there is concern that the population is at risk of a measles epidemic, resulting from low vaccination rates before the typhoon struck. "With no budget, no electricity, and so many other repairs that need doing, we don't know where to start."
Yet there is some hope for this battered population, including support from the international charity Doctors of the World. It already had a small group of volunteers engaged in an environmental health project in the country. After the typhoon they switched roles and initiated an early collaboration with the Philippines' health department. Within hours, the charity had organised the immediate dispatch of 50 tonnes of medical supplies as well as moving an experienced, specialist team of 19 volunteers - surgeons, doctors, nurses, midwives, and health visitors - to supervise the disaster initiative.

The ambitious aim now is to mobilise and equip the highly skilled local Filipino health workforce to provide immediate care for bereft communities in five cities and 30 remote villages in northern Leyte, the island that took the greatest battering from Haiyan. The charity will operate from a base in Ormoc, a large northern city where four out of five hospitals were obliterated in just a few minutes when the typhoon struck.

On 22 November Manuel de Lara, a French public health specialist and the charity's medical coordinator in the Philippines disaster area, received the charity's first shipment, which included 10 "disaster kits." The kits cost about $£ 3000$ ( $€ 3600$; $£ 4900$ ) and contain supplies, including drugs for common chronic disorders, vaccinations, and children's vitamins, to meet the everyday healthcare needs of 1000 people for three months. Five mobile medical teams are currently distributing the kits to remote areas with medical staff that can speak the local dialect, travelling through tough terrain in four by four vehicles and helicopters where necessary. "It's still early days, but we are already treating patients and making a difference. Of course, many more of these kits are needed, along with the funds to support our long term plan to rehabilitate local services," de Lara told the $B M J$. 


\section{Using local resources}

Doctors of the World has a 30 year record of organising teams of unpaid medical volunteers to mount an immediate response to humanitarian emergencies. Its aim is to support the most vulnerable people affected by natural disasters as well as war, disease, hunger, or poverty by mobilising, equipping, and, where necessary, training the local health workforce rather than substituting for local services.

Made up of 14 independent national organisations, the charity currently has 3000 volunteer doctors, surgeons, nurses, managers, and health workers who are working in more than 300 programmes in 70 countries, many of which are long term, fulfilling the charity's overall mission of "building back better."

"At times of disaster, the priority is to bring about normality in the health service, particularly for pregnant women and children under 5," de Lara said.

So alongside the purely medical support, volunteers supervise the provision of psychosocial support, sexual and reproductive health services, and community care for women and children.

The charity has had plenty of opportunities to develop expertise. "A similar initiative has been in operation in Mali since the emergency a year ago," says Leigh Daynes, the charity's executive director in London. As in the Philippines, the charity was already involved in long term health development, and then, "with the sudden build-up of refugees suffering food insecurity, we were able to switch to a huge $€ 5 \mathrm{~m}$ programme, building capacity through training and support of 300 Malian healthcare staff."

Other similar initiatives have taken place in Haiti, where 1200 Doctors of the World workers, of whom $95 \%$ are Haitian, have organised 250000 consultations and medical procedures to manage the recurring cholera epidemics since the earthquake struck in January 2010.

More recently, the charity has helped closer to home, with major initiatives in Athens, where one in five people are living below the poverty line and where families with children but without health insurance cannot afford basic medical care. A clinic and advocacy programme provides medical care, information, and practical support to vulnerable migrants, sex workers, and people with no fixed address. It runs a similar clinic in Bethnal Green, east London.

The achievements of Doctors of the World rely, of course, on donations. "Working with volunteers means we can be nimble and efficient while keeping costs down," says Daynes. "But it's a long haul. Meeting immediate medical needs in the Philippines is a sprint; rebuilding the country's health system will be a marathon. However donations are used, we can guarantee that every penny you donate will be spent wisely and well," he says. "Please give generously this Christmas."

Cite this as: BMJ 2013;347:f7193

\section{Related links}

\section{bmj.com}

- Blog by Leigh Daynes: How Doctors of the World is helping in the Philippines

- Listen to a podcast discussing our Christmas appeal at bmj. com/multimedia

(c) BMJ Publishing Group Ltd 2013 


\section{To donate to Doctors of the World}

A donation of $£ 125$ could help 50 children with severe malnutrition in the Philippines. To donate go to www.doctorsoftheworld.org.uk/BM $\rfloor$ or phone +44 (0)20 35357955 . To donate $£ 10$ by text message: text DOCTOR to 70030 (UK mobiles only).

\section{Figure}

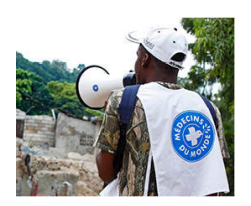

[Image: MDM] 